\title{
JOURNAL OF WELLNESS
}

\author{
EDITORIAL
}

\section{Wellness Review 2019, Part 1}

\author{
Martin Huecker $\mathrm{MD}^{* *}$ and Brian Ferguson DO ${ }^{1,2}$, Editors-in-Chief \\ DOI: 10.18297/jwellness/vol1/iss1/4 Website: https://ir.library.louisville.edu/jwellness/ \\ Affiliations: 'University of Louisville, Department of Emergency Medicine, ${ }^{2}$ Keesler Air Force \\ Base, Emergency Department \\ Recommended Citation: Huecker, Martin and Ferguson, Brian A. (2019) "Wellness Review 2019 \\ Part 1," Journal of Wellness: Vol. 1 : Iss. 1 , Article 4.
}

\section{INTRODUCTION}

Welcome to the first Journal of Wellness review of recent literature. Wellness leaders are aware that a literature search yields thousands of articles on burnout, less on wellness, and no consistent, reliable source of publication. This validates the mission of JWellness, to collect editorials and research in one location, free for all to read and publish, allowing dissemination to all healthcare professionals.

For this review, we searched Pubmed from January to June (2019) for keywords "burnout," "wellness," "well-being," in "physicians" and "healthcare professionals." Out of the hundreds of articles, we selected a reasonable amount that investigated or commented specifically on the well-being of healthcare professionals in various disciplines. Our review will provide a superficial overview of each, and we encourage you to follow the source references for application of concepts. Papers not described in the article have brief explanations in the references section [1-7]. We hope to provide some answers, but we intend to inspire more questions and welcome letters to confirm, criticize, or expand on this content.

\section{LITERATURE REVIEW}

Common themes in current wellness publications include individual versus system responsibilities, the financial benefits of a healthy workforce, and wellness as distinct from the absence of burnout. JWellness believes we should focus efforts not on staying above water, but on thriving. We will begin with those publications that endeavor to enhance the wellness of healthcare professionals, then move on to burnout.

\section{WELLNESS INTERVENTIONS}

Dunne et al published a study of Attention Based Training, a clinical term for Transcendental Meditation [8]. Participants received four 4-hour sessions on TM training and were expected to perform two 20-minute

${ }^{*}$ Correspondence To: Martin Huecker, MD

Email: martin.huecker@louisville.edu mantra repeating sessions per day (maranatha). They all used a smartphone app and wore a heart rate capable activity tracker. Versus the control group, the TM group had lower burnout scores (specifically EE), and less stress and anxiety. The intervention group also had improved heart rate variability, resting heart rate, sleep, and inflammatory cytokines. Of note, only $13 \%$ of subjects reached the target TM time by the last week, and attendance at the training sessions went down over time.

Using randomized controlled design, researchers attempted to reduce burnout and anxiety among physicians [9]. They taught 227 doctors about the psychology of burnout, stress, and coping mechanisms. Subjects took a comprehensive survey, then participated in one of three different modules or all three or none. The subjects who participated in all three modules (one week) had significantly decreased emotional exhaustion, depersonalization, and anxiety.

Another group slapped activity trackers (Fitbit Charge HR) on 30 residents to look at several variables related to training [10]. Using a validated single item burnout survey, they found no association between amount of call and training satisfaction, emotional exhaustion, burnout, or sleep quality. There was no significant association between time in bed, time asleep, times awakened, or sleep latency and call load. Maybe we can't blame the hard work itself.

Ott-Holland et al performed a review of employees $(17,245$ people) at branches of a US financial institution in Midwest during a three-year physical health and wellness program [11]. This is a densely packed article with a fair amount of technical jargon. Authors found perceived value of the program and organizational support correlated with participation - the more faith you have in a program and your institution, the more likely you are to join. Participants had higher job satisfaction, intention to stay in their jobs, and objectively lower turnover than non-participants (effects on job satisfaction and intention to stay disappeared when controlled for beliefs

Copyright: ( 2019 The author(s). This is an open access article distributed under the terms of the Creative Commons Attribution 4.0 International License (CC BY 4.0), which permits unrestricted use, distribution, and reproduction in any medium, provided the original author and source are credited. 
prior to the study period). Pay attention to the practical and ethical implications sections of this article. Organizations should assess beliefs via a presurvey, to see if a program will be well received and to assess health consciousness. Workers who are more health conscious are more likely to participate. Leadership should also consider enlisting enthusiastic employees or past participants as program advocates. The ethics section discusses subgroup differences, how under-represented minorities may be less likely to participate, how "voluntary" participation might be misleading, and how more healthy employees find it easier to participate.

The Ohio State published a paper in a clinical OB/ GYN journal looking at interventions to reduce burnout and improve resilience and health system outcomes [12]. Using tools such as Crew Resource Management (an aviation concept), Mindfulness in Motion (MIM) and flipped classroom mindfulness training, the project was feasible, improved compassion, and reduced burnout. Table 1 shows cost savings from reduced events such as falls, CLABSI, etc. This article was interesting for its emphasis on interventions in healthcare professionals leading to measurable, financial gains for the larger healthcare system.

Pearson and Frakt wrote a short piece in JAMA Forum on scribes, productivity and satisfaction [13]. They referenced Atul Gawande's quote from the New Yorker, that the scribe "fix is ridiculous" ... paper was inefficient so we got computers, computers were inefficient so we hired more humans...but it "sort of works" [14]. Scribes save clinicians time both during and outside of clinical hours, and they increase productivity. Effects on patient satisfaction are less clear. The doctor can focus on the patient, perhaps communicate more effectively, but patients must accept another stranger in the room [13].

A small systematic review summarized effects of system-wide physical activity interventions on occupational stress [15]. The nine studies (all low quality) involved yoga, Tai Chi, qigong, or general workplace activity. They found a suggested stress reducing effect of yoga and qigong, but no effect in general workplace activity or yoga. Table 2 displays the nine studies and provides information on subjects, interventions and outcomes.

Fang et al studied work stress and humor in association with health status in 236 Taiwanese hospital nurses [16]. The intervention was simply to pay attention to humor, provide nurses with "musical CDs or humorous books," and stress management training. They commented on predictors of having a "health problem" (referring to physical symptoms that may or may not have led to seeking healthcare). Health problems were more common in subjects with significant life events occurring in the past three months, high work stress, and low humor.

Stuart Slavin wrote a concisely packed article on wellness and an alternative path to conquer burnout [17]. The individual and the system must work together for solutions, but the individual can take Victor Frankl's advice to find meaning in daily work. Slavin encourages job diversification: professional consultations, manage- ment, student interactions, research. A 2013 article on 89k physicians showed less burnout in academia, with minimal mid-career jump in burnout that was common in non-academic settings [18]. Slavin's references 11-14 relate to programs on narrative medicine and other humanities initiatives. This piece parallels the Mukharjee New York Times Magazine article advising us to prevent burnout by "burning a little more, ... finding powerful, autonomous interests ... in peculiar medical niches" [19].

Researchers in Mexico added to Carol Dweck's mindset work by studying 1240 undergraduate college students [20]. Students with higher growth mindset (on a scale from fixed to growth) had higher well-being and performed better in school. Authors note no prior work testing the effect of a growth mindset on well-being. Well-being was measured using Seligman's PERMA model. If you work with medical students, these are your learners coming right out of college.

An exploratory case study of mental toughness variability and potential influencers followed 10 master runners (men and women, avg. age 48yo) during a month of training [21]. Mental toughness varied significantly over time, manifesting as a state rather than trait. They created a Mental Toughness Index (MTI) and found three higher themes that interact: Thrive, Prepare, Activate. They also introduced the terms capacity mental toughness and functional mental toughness. Similar to lung physiology, we hold some residual capacity for mental toughness in reserve that can be accessed when needed. We would argue that the best way to improve at accessing this toughness (and build reserve) is to practice [22].

\section{BURNOUT DESCRIPTION}

A summary of burnout literature appeared in Cureus (an "open access medical journal for a new generation of doctors and patients' appeal to the cross-disciplinary nature of medicine") [23]. We highlight this thorough review of the literature for its content, but also to draw our readers to the journal Cureus, which like JWellness, appears too good to be true. Authors reviewed measurement instruments, physician vs system initiatives, a description of coaching, and cultivation of an internal locus of control.

Han et al published a thorough, thought-provoking piece on the cost of physician burnout in the US [24]. With a "cost-consequence analysis using a mathematical model," they simulated a hypothetical system of 1000 doctors. At current rates, burnout cost the system $\$ 4.6$ billion due to turnover and reduced clinical hours (range $\$ 2.6-6.3$ billion). They chose these outcomes because they "directly affect the net supply of clinical capacity which in turn is an important consideration for strategic planning." Tables show replacement cost, vacancy adjusted revenue loss, reduction in clinical hours in three physician categories: primary care, surgeons, and other specialties.

We saw a publication this year from JWellness's own Dr. Ronald Epstein on the often-confused distinction 
between burnout and depression [25]. Dr. Epstein points out that work as a physician is stressful and always will be. Adaptive traits of physicians (perfectionism, obsessiveness, self-neglect) backfire and lead to burnout. $\mathrm{He}$ recommends Mindfulness Based Stress Reduction (MBSR) and Cognitive Behavioral Therapy (CBT) to enhance self-actualization, self-awareness, and self-compassion. National Physician Suicide Awareness Day was September 17, and The Medscape National Physician Burnout, Depression \& Suicide Report 2019 provides sobering but important data on this problem. The most common coping mechanism for burnout was exercise $48 \%$, and $64 \%$ of doctors have not sought help for burnout or depression [26].

A thoughtful article on burnout, drop out, and suicide in emergency medicine physicians appeared in Western Journal of Emergency Medicine [27]. Part I (of II) looks at causes of burnout, consequences of burnout, and lastly at unique aspects of emergency medicine (a good resource for everyone in healthcare). We look forward to Part II - mitigating burnout and wellness, 'anti-burnout,' but are not exactly comfortable with the term anti-burnout. Does elimination of burnout signify the presence of wellness? If you are no longer burned out are you actually thriving?

A metasynthesis and literature review of qualitative studies on physician perspectives reviewed 33 articles with 1589 subjects [28]. The very large Table 1 displays characteristics of all of these studies, across 15 countries, with median 22 subjects, but many with several hundred doctors. Two themes emerged: 1) Factors promoting burnout were mostly organizational and 2) Protective factors were mostly individual.

Daniel Marchalik (office of physician well-being and literature and medicine at Georgetown) wrote on the past and future of burnout in The Lancet [29]. He reminds us of a 2014 study that showed medical students had more reserve entering medical school but had higher depression/burnout on graduating (compared to non-medical school controls). Professional degrees protect against burnout in all fields except medicine. Marchalik wonders if we are in a "burnout renaissance," citing the recent increased awareness. "Burnout is as dynamic as medicine itself," where we solve old challenges but see new ones creeping in. He urges leaders to be creative and keep physician wellness as a "standing agenda item" in a preemptive approach.

A very interesting study looked at burnout among 678 obstetricians and pediatricians in 11 hospitals in China [30]. They found a burnout rate of $56.6 \%$, with poor doctor-patient relationships, low family support, and high average weekly hours as major contributors.

Interestingly, the national shift to a two-child allowance has led to significantly higher numbers of births per year. This increased demand for services was not matched with a corresponding increase in healthcare providers. Readers in other countries could reflect on this: if our patient volumes doubled over a brief period of time, how would we handle it?

Surgeons "take a sad song and make it better" with their cross-sectional national survey on burnout [31]. Authors obtained 1927 survey responses (17\% response rate) from in-training and attending surgeons. As in other studies, residents exhibited more depersonalization. Surgical fellows had the lowest overall burnout rates, and the career trajectory was optimistic, with less burnout as career progresses: "residency training is the nadir of personal wellness in a physician's career." Does life for the surgeon improve over time, or does the harsh training facilitate comparative happiness once finished? Authors offer solutions to burnout, aptly highlighting the palatability of 'coaching' compared to therapy. Vascular surgeons in training also received some attention with a study out of Ann Arbor, Michigan [32]. They recommend acknowledging burnout, mentorship, self-care, and access to resources for stress-reduction. Trainees need trustworthy faculty that encourage small victories, receptive leaders, and development of resilience.

French physicians struggle with burnout, at a rate of 49\% [33]. A large meta-analysis reviewed 37 studies on burnout in France. Emergency physicians trended toward higher rates and more severe burnout, having the highest level of depersonalization and the lowest levels of empathy. Residents had higher depersonalization, with junior resident status and monthly night shifts correlating with lower personal accomplishment. Anesthesiologists also had high emotional exhaustion and depersonalization. Check out Table 2 for summary of the individual variable meta-regression model. The only factor correlated with burnout on multivariate meta-regression was study quality: higher study quality predicted burnout. From the authors: "Finding similar rates of burnout in French and US physicians was unexpected, because of discrepancies between systems." Was this really unexpected? What is ubiquitous in the modern practice of medicine that leads to burnout all over the world?

\section{CONCLUSION}

We still have much work to do in recognizing and treating burnout on both individual and system levels. Burnout does not discriminate based on salary, healthcare profession, level of training, or country. The healthcare professions literature maintains a disproportionate focus on description of burnout, with a small (but increasing) number of studies on mitigating burnout. Studies continue to frame strategies as combating burnout, rather than enhancing wellness and promoting thriving in the workplace. 


\section{REFERENCES}

1. Altınışık HB, Alan H. Compassion Fatigue, Professional Quality of Life, and Psychological Endurance Among Organ Transplant Coordinators. Transplant Proc. 2019 May;51(4):1038-43.

Studied 91 transplant coordinators in Turkey, reviewing compassion fatigue, QOL, and psychological endurance. They found a significant positive correlation between burnout and compassion fatigue/traumatic stress subscales of the ProQOL. High levels of QOL and psych endurance are protective of compassion fatigue What is compassion fatigue? Can you run out of compassion? Is it zero sum, finite? Can you measure compassion or it's depletion?

2. Cho E, Jeon S. The role of empathy and psychological need satisfaction in pharmacy students' burnout and well-being. BMC Med Educ. 2019 Feb;19(1):43.

Interesting article on empathy and psychologic need satisfaction in pharmacy students in South Korea. They surveyed 452 students and had a survey completion rate of $98.9 \%$ ! Empathy was positively associated with well-being. Perceived satisfaction of psychologic needs was positively correlated with well-being and negatively correlated to burnout. Internationally, pharmacists are investigating burnout, and are apparently very conscientious survey participants.

3. McGonigal M, Bauer M, Post C. Physician Engagement: A Key Concept in the Journey for Quality Improvement. Crit Care Nurs Q. 2019 Apr/ Jun;42(2):215-9.

Broad look at a healthcare organization, pointing out that while physicians act as captains of the ship, the 'crew rowing the boat' impacts patient outcomes. They chose physicians as 'volunteers' on committees to tackle four quality improvement problems. Eventually, physicians (including residents) were requesting to join the cross-disciplinary teams, and the initiative showed concrete benefits to quality improvement.

4. Mull CC, Thompson AD, Rappaport DI, Gartner JC Jr, Bowman WR. A Call to Restore Your Calling: Self-Care of the Emergency Physician in the Face of Life-Changing Stress-Part 3 of 6: Physician Illness and Impairment. Pediatr Emerg Care. 2019 Aug;35(8):585-8.

First of six articles on restoring your calling in medicine, in Pediatric Emergency Care. The first article dives into the impact of death of a patient. Looking forward to more.
5. Panari C, Caricati L, Pelosi A, Rossi C. Emotional exhaustion among healthcare professionals: the effects of role ambiguity, work engagement and professional commitment. Acta Biomed. 2019 Jul;90 6-S:60-7.

This small study looked at 66 healthcare professionals in different roles to determine role ambiguity and its relation to EE and decreased job satisfaction. Bottom line, organizations should remove hindrances and enhance the coherence of the mission.

6. Winkel AF, Robinson A, Jones AA, Squires AP. Physician resilience: a grounded theory study of obstetrics and gynaecology residents. Med Educ. 2019 Feb;53(2):184-94.

Paper on resilience grounded theory in OBGYN residents. They used a theoretical approach and created a nice tree-themed conceptual model (Figure 1). Authors recognized the importance of professional identity and purpose, connections inside and outside of medicine, and finding meaning.

7. 7. Yester M. Work-Life Balance, Burnout, and Physician Wellness. Health Care Manag (Frederick). 2019 Jul/Sep;38(3):239-46.

Narrative review of studies on work-life balance effects on wellness, separating into individual, organization, and system. Physicians (really all healthcare professionals!) sacrifice health, ignoring the advice we give to patients on regular healthcare appointments, proper screening, etc. Authors suggest we deliver wellness strategies earlier in medical school / training.

8. Dunne PJ, Lynch J, Prihodova L, O'Leary C, Ghoreyshi A, Basdeo SA, et al. Burnout in the emergency department: randomized controlled trial of an attention-based training program. J Integr Med. 2019 May;17(3):173-80.

9. Medisauskaite A, Kamau C. Reducing burnout and anxiety among doctors: randomized controlled trial. Psychiatry Res. 2019 Apr;274:383-90.

10. Marek AP, Nygaard RM, Liang ET, Roetker NS, DeLaquil M, Gregorich S, et al. The association between objectively-measured activity, sleep, call responsibilities, and burnout in a resident cohort. BMC Med Educ. 2019 May;19(1):158.

11. 11. Ott-Holland CJ, Shepherd WJ, Ryan AM. Examining wellness programs over time: predicting participation and workplace outcomes. J Occup Health Psychol. 2019 Feb;24(1):163-79. 
12. Moffatt-Bruce SD, Nguyen MC, Steinberg B, Holliday S, Klatt M. Interventions to Reduce Burnout and Improve Resilience: Impact on a Health System's Outcomes. Clin Obstet Gynecol. 2019 Sep;62(3):432-43.

13. Pearson E, Frakt A. Medical Scribes, Productivity, and Satisfaction. JAMA. 2019 Feb;321(7):635-6.

14. Gawande A. Why Doctors Hate Their Computers. The New Yorker. November 5, 2018. https://www. newyorker.com/magazine/2018/11/12/why-doctors-hate-their-computers. Accessed September 26, 2019.

15. Bischoff LL, Otto AK, Hold C, Wollesen B. The effect of physical activity interventions on occupational stress for health personnel: A systematic review. Int J Nurs Stud. 2019 Sep;97:94-104.

16. Fang L, Hsiao LP, Fang SH, Chen BC. Associations of work stress and humor with health status in hospital nurses-A cross-sectional study. J Clin Nurs. 2019 Oct;28(19-20):3691-9.

17. Slavin S. Preventing physician burnout: satisfaction or something more? Isr J Health Policy Res. 2019 Mar;8(1):34.

18. Dyrbye LN, Varkey P, Boone SL, Satele DV, Sloan JA, Shanafelt TD. Physician satisfaction and burnout at different career stages. Mayo Clin Proc. 2013 Dec;88(12):1358-67.

19. Mukharjee S. For Doctors, Delving Deeper as a Way to Avoid Burnout. In. The New York Times Magazine 2018. https://www.nytimes.com/2018/10/10/ magazine/for-doctors-delving-deeper-as-a-way-toavoid-burnout.html. Accessed 9-26-19.

20. Ortiz Alvarado NB, Rodríguez Ontiveros M, Ayala Gaytán EA. Do Mindsets Shape Students' Well-Being and Performance? J Psychol. 2019;153(8):84359.

21. Cooper KB, Wilson M, Jones MI. An Exploratory Case Study of Mental Toughness Variability and Potential Influencers over 30 Days. Sports (Basel, Switzerland). 2019;7(7).

22. Deuster PA, Silverman MN. Physical fitness: a pathway to health and resilience. US Army Med Dep J. 2013 Oct-Dec: $24-35$.
23. Patel RS, Sekhri S, Bhimanadham NN, Imran S, Hossain S. A Review on Strategies to Manage Physician Burnout. Cureus. 2019 Jun;11(6):e4805.

24. Han S, Shanafelt TD, Sinsky CA, Awad KM, Dyrbye LN, Fiscus LC, et al. Estimating the Attributable Cost of Physician Burnout in the United States. Ann Intern Med. 2019 Jun;170(11):784-90.

25. Epstein RM, Privitera MR. Addressing physician mental health. Lancet Psychiatry. 2019 Mar;6(3):190-1.

26. Kane L. Medscape National Physician Burnout, Depression \& Suicide Report 2019. News and Perspective Web site. https://www.medscape.com/slideshow/2019-lifestyle-burnout-depression-6011056. Published 2019. Accessed 9-26-19.

27. Stehman CR, Testo Z, Gershaw RS, Kellogg AR. Burnout, Drop Out, Suicide: Physician Loss in Emergency Medicine, Part I. West J Emerg Med. 2019 May;20(3):485-94.

28. Sibeoni J, Bellon-Champel L, Mousty A, Manolios E, Verneuil L, Revah-Levy A. Physicians' Perspectives About Burnout: A Systematic Review and Metasynthesis. J Gen Intern Med. 2019 Aug;34(8):1578-90.

29. Marchalik D. Physician burnout in the modern era. Lancet. 2019 Mar;393(10174):868-9.

30. Ye J, Wang H, Wu H, Ye L, Li Q, Ma XY, et al. Burnout among obstetricians and paediatricians: a cross-sectional study from China. BMJ Open. 2019 Jan;9(1):e024205.

31. Jackson T, Morgan J, Jackson D, Cook T, McLean K, Agrawal V, et al. Trends in Surgeon Wellness (Take a Sad Song and Make It Better): A Comparison of Surgical Residents, Fellows, and Attendings. Am Surg. 2019 Jun;85(6):579-86.

32. Audu CO, Coleman DM. Prioritizing personal well-being during vascular surgery training. Semin Vasc Surg. 2019 Mar - Jun;32(1-2):23-6.

33. Kansoun Z, Boyer L, Hodgkinson M, Villes V, Lançon C, Fond G. Burnout in French physicians: A systematic review and meta-analysis. J Affect Disord. 2019 Mar;246:132-47. 